\title{
Publisher Correction: Clinical use of current polygenic risk scores may exacerbate health disparities
}

\author{
Alicia R. Martin (D), Masahiro Kanai (D), Yoichiro Kamatani (D), Yukinori Okada (D), Benjamin M. Neale (D) and Mark J. Daly (iD) \\ Correction to: Nature Genetics https://doi.org/10.1038/s41588-019-0379-x, published online 29 March 2019. \\ In the version of this article initially published, in the legend to Fig. 4, the descriptions of panels $\mathrm{d}$ and e were switched, although the \\ figure itself is labeled correctly; panel d shows data for British individuals in the UKBB, and panel e shows data for Japanese individuals \\ in the BBJ. In addition, the copyright line read 'The Author(s), under exclusive licence to Springer Nature America, Inc.' but should have \\ read 'Springer Nature America, Inc.' The errors have been corrected in the HTML and PDF versions of the article.
}

Published online: 28 January 2021

https://doi.org/10.1038/s41588-021-00797-Z

( ) Springer Nature America, Inc. 2021

\section{Publisher Correction: Mutation load at a mimicry supergene sheds new light on the evolution of inversion polymorphisms}

Paul Jay D, Mathieu Chouteau D, Annabel Whibley, Héloïse Bastide, Hugues Parrinello, Violaine Llaurens and

Mathieu Joron (D)

Correction to: Nature Genetics https://doi.org/10.1038/s41588-020-00771-1, published online 25 January 2021.

In the version of this article initially published, in Fig. 2a, the label 'Insertions in inversions compared with noninverted segments' appeared to apply to all six of the inversion boxes but should have labeled only the three rightmost boxes. The error has been corrected in the HTML and PDF versions of the article.

Published online: 5 February 2021

https://doi.org/10.1038/s41588-021-00810-5

(c) The Author(s), under exclusive licence to Springer Nature America, Inc. 2021 